\title{
Análisis de Diversidad Genética de Cepas de Pasteurella multocida Aisladas de Alpacas con Signos de Neumonía
}

\author{
Genetic Diversity Analysis of Pasteurella multocida Isolates from Alpacas with \\ Clinical Signs of Pneumonia
}

\author{
Rocío Rímac B. ${ }^{1}$, Raquel Hurtado C. ${ }^{1}$, Luis Luna E. ${ }^{\text {, }}$ Raúl Rosadio A. ${ }^{1}$, \\ Lenin Maturrano H. ${ }^{1,2}$
}

\section{Resumen}

El propósito del estudio fue caracterizar cepas de Pasteurella multocida aisladas de pulmones de alpacas de 1 a 2 meses de edad con signos de neumonía, colectados en 2014. Se utilizó la técnica de BOX-PCR para demostrar la diversidad genética entre las cepas. Se aislaron 24 cepas de $P$. multocida de 46 animales mediante identificación bioquímica. El análisis por BOX-PCR demostró dos patrones de bandas amplificadas, donde 22 cepas fueron agrupadas en un clúster y dos cepas en otro clúster. El presente estudio demostró una homogeneidad genética en la mayoría de las cepas, evidenciando una fuente común de infección que afectó a los animales.

Palabras clave: Pasteurella multocida; BOX-PCR; diversidad genética; neumonía; alpaca

\section{Abstract}

The purpose of this study was to characterize strains of Pasteurella multocida isolated from lungs of 1-2 months old alpacas with signs of pneumonia, collected in 2014. The BOX-PCR technique was used to demonstrate genetic diversity among strains. Twenty-four strains of $P$. multocida were isolated from 46 animals through biochemical identification tests. The BOX-PCR analysis showed two amplified band patterns, where 22 strains were grouped in one cluster and two strains in another cluster. The present study showed genetic homogeneity in most of the strains, evidencing a common source of infection that affected the animals.

Key words: Pasteurella multocida; BOX-PCR; genetic diversity; pneumonia; alpaca

\footnotetext{
${ }^{1}$ Sección de Biología y Genética Molecular, Laboratorio de Microbiología y Parasitología Veterinaria, ${ }^{2}$ Laboratorio de Zootecnia y Producción Agropecuaria, Facultad de Medicina Veterinaria, Universidad Nacional Mayor de San Marcos, Lima, Perú

${ }^{3}$ E-mail: lenin.maturrano@gmail.com
}

Recibido: 7 de noviembre de 2016

Aceptado para publicación: 23 marzo de 2017 


\section{INTRODUCCIÓN}

Los camélidos sudamericanos son el principal recurso económico para las comunidades andinas del Perú; sin embargo, la eficiencia productiva de estos animales se encuentra afectada por procesos entéricos y pulmonares, entre ellos la neumonía, ocasionando altos porcentajes de mortalidad (Ameghino y De Martini, 1991).

Pasteurella multocida, miembro normal de la microbiota nasal de alpacas adultas (Barsallo, 1985), es un agente bacteriano frecuentemente aislado de casos de neumonía en alpacas (Cirilo, 2008), de allí que se sugiere que eventos de estrés potenciados por factores ambientales como la época de lluvias y las heladas (Ameghino y De Martini, 1991) facilitarían su multiplicación y la colonización de los alveolos pulmonares, especialmente en animales inmunosuprimidos (Yates, 1982); donde es posible aislar este agente bacteriano del tejido pulmonar (Guzmán, 2011; Rosadio et al., 2011).

Estudios realizados en $P$. multocida de alpacas se basan principalmente en la detección e identificación microbiológica; sin embargo, no existe información acerca de la diversidad de las cepas que pueden afectar a un grupo de animales susceptibles. Dagleish et al. (2016) describen cepas de P. multocida aisladas de bovinos de Gran Bretaña y Estados Unidos, correlacionando el perfil genético con el grado de patogenicidad, mediante la técnica PFGE (Electroforesis de Campo Pulsado), destacando la importancia del análisis de diversidad entre cepas, no solo para una determinación rápida de perfil patogénico, sino además para el desarrollo de vacunas.

La técnica molecular PFGE es la técnica «Gold Standard» para la evaluación de la diversidad genética por su alto poder discriminatorio (Foxman et al., 2005), pero requiere de equipos costosos y muy complejos. Por ello, una alternativa para el análisis de diversidad es el uso de la técnica rep-PCR (Amplificación por PCR de elementos repetitivos), basada en la amplificación por cebadores (primers) randómicos de las secuencias repetitivas del genoma bacteriano, lo cual genera un patrón de bandas de distintos pesos moleculares y permite obtener una huella digital (fingerprinting) del aislado. La técnica de rep-PCR emplea distintas secuencias para cebadores, entre ellos, el BOX-PCR (Martin et al., 1992; Versalovic et al., 1994; Ishii y Sadowsky, 2009).

La técnica rep-PCR ha sido empleada en el análisis de diversidad genética de aislados de Mannheimia haemolytica, bacteria que también ha sido involucrada en la neumonía en alpacas. En un estudio de 22 asilados de EEUU y 36 aislados de Australia provenientes de tejido pulmonar de bovinos que fallecieron por la Enfermedad Respiratoria Bovina, se encontró que la técnica de BOXPCR tuvo más poder discriminatorio que el secuenciamiento del gen 16 sARN, detectándose diversi dad entrelosai slados del mismo país y entre continentes (Taylor et al, 2014). Por ello, el presente estudio tuvo como objetivo emplear la técnica BOX-PCR para detectar diversidad genética a partir de 24 cepas de $P$. multocida de crías de alpacas con signos de neumonía.

\section{Materiales y Métodos}

\section{Lugar del Estudio}

Fueron analizados un total de 24 cepas de P. multocida aisladas de crías de alpacas con signos neumónicos del centro experimental La Raya - Universidad del Altiplano (UNA), en el departamento de Puno, Perú, en 2014. El procesamiento y análisis de las muestras se realizaron en las instalaciones de la Sección de Biología y Genética Molecular de la Facultad de Medicina Veterinaria (FMV) de la Universidad Nacional Mayor de San Marcos (UNMSM), Lima. 


\section{Material del Estudio}

Los aislados provinieron de un grupo de 46 animales con signos neumónicos provenientes de un grupo o «punta» de alpacas Suri $(\mathrm{n}=14)$ y de dos «puntas» de Huacayas $(\mathrm{n}=32)$. De estos aislados, solo 24 fueron positivos a $P$. multocida (6 Suris y 18 Huacayas) por análisis microbiológico y por el sistema API 20NE (Biomerux). Los animales tenían entre 1 y 2 meses de edad.

Dos cepas de P. multocida aisladas de ovino (V25 y V26), que fueron donados por la Universidad Complutense de Madrid (España), fueron empleados como cepas de referencia para la identificación bioquímica. También se emplearon dos cepas de E. coli (EPEC) (V27 y V28) aisladas de alpacas sin diarrea para la elaboración de un dendograma, y provenientes del cepario de la Sección de Biología y Genética Molecular, FMV-UNMSM.

\section{Extracción de ADN}

Los aislados de P. multocida de alpaca, ovino y $E$. coli fueron cultivadas en $1 \mathrm{ml}$ de caldo infusión cerebro-corazón (BHI, MERCK) a $37^{\circ} \mathrm{C}$ por $24 \mathrm{~h}$, en condiciones aeróbicas. Posteriormente se realizó la extracción de ADN con el Wizard Genomic DNA Purification Kit (Promega), siguiendo las instrucciones del fabricante.

\section{Análisis de Diversidad Genética por BOX-PCR}

Las cepas fueron analizadas mediante la técnica BOX-PCR empleando los cebadores descritos por Versalovic et al. (1994). La reacción consistió en un volumen final de $20 \mu 1$ con $1 \mu \mathrm{M}$ de dNTPs, $3 \mathrm{mM}$ de $\mathrm{MgCl}_{2}, 2 \mu \mathrm{M}$ del cebador, $1.5 \mathrm{U}$ de Taq polimerasa y $2 \mu \mathrm{l}$ de muestra de ADN. Las condiciones de la PCR fueron: $95{ }^{\circ} \mathrm{C}$ por 5 min para una desnaturalización inicial, seguido por 30 ciclos de $94{ }^{\circ} \mathrm{C}$ por $3 \mathrm{~s}, 92^{\circ} \mathrm{C}$ por $30 \mathrm{~s}, 50^{\circ} \mathrm{C}$ por $1 \mathrm{~min}$ y $65^{\circ} \mathrm{C}$ por $8 \mathrm{~min}$, con una extensión final de $65^{\circ} \mathrm{C}$ de $8 \mathrm{~min}$. El cebador utilizado fue BOX A1R cuya secuencia es CTA CGG CAA GGC GAC GCT GAC G.

Los productos de PCR obtenidos fueron analizados por medio de electroforesis en gel de agarosa ( $3 \%$ de agarosa en $0.5 \mathrm{X}$ TBE) por $4 \mathrm{~h}$ y teñido con bromuro de etidio para su posterior visualización en un transluminador UV.

\section{Dendograma}

Se realizó el análisis de agrupamiento (clusters) para generar el dendograma mediante el programa NTSYSpc $2.10 \mathrm{~m}$, em-

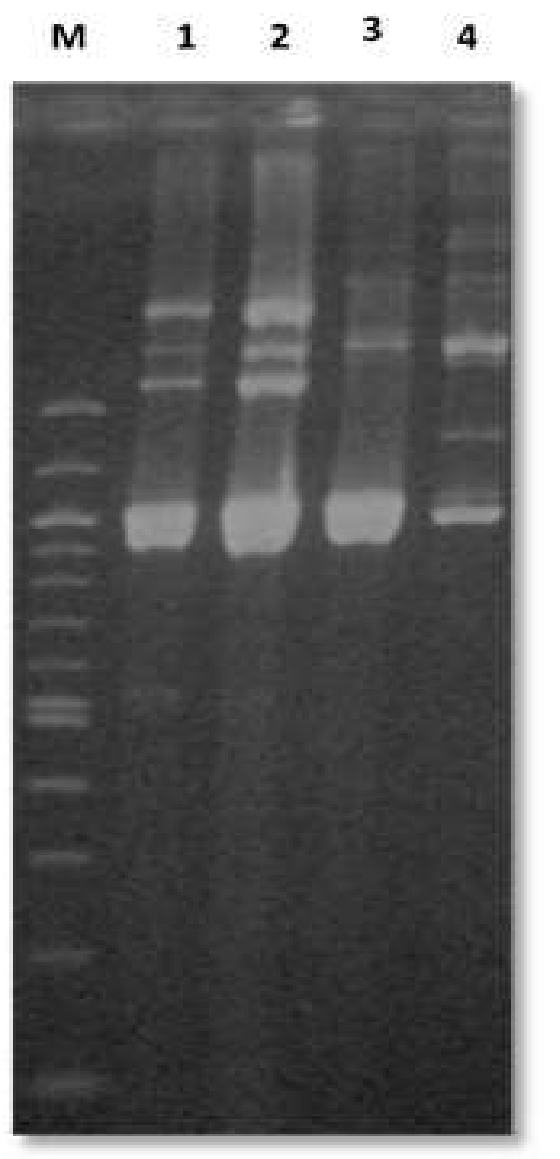

Figura 1. Análisis por BOX-PCR de cepas de Pasteurella multocida de alpacas y ovinos. M: marcador de $100 \mathrm{pb}$. Carril 1,2: cepas de alpaca. Carril 3,4: cepas control de ovino 


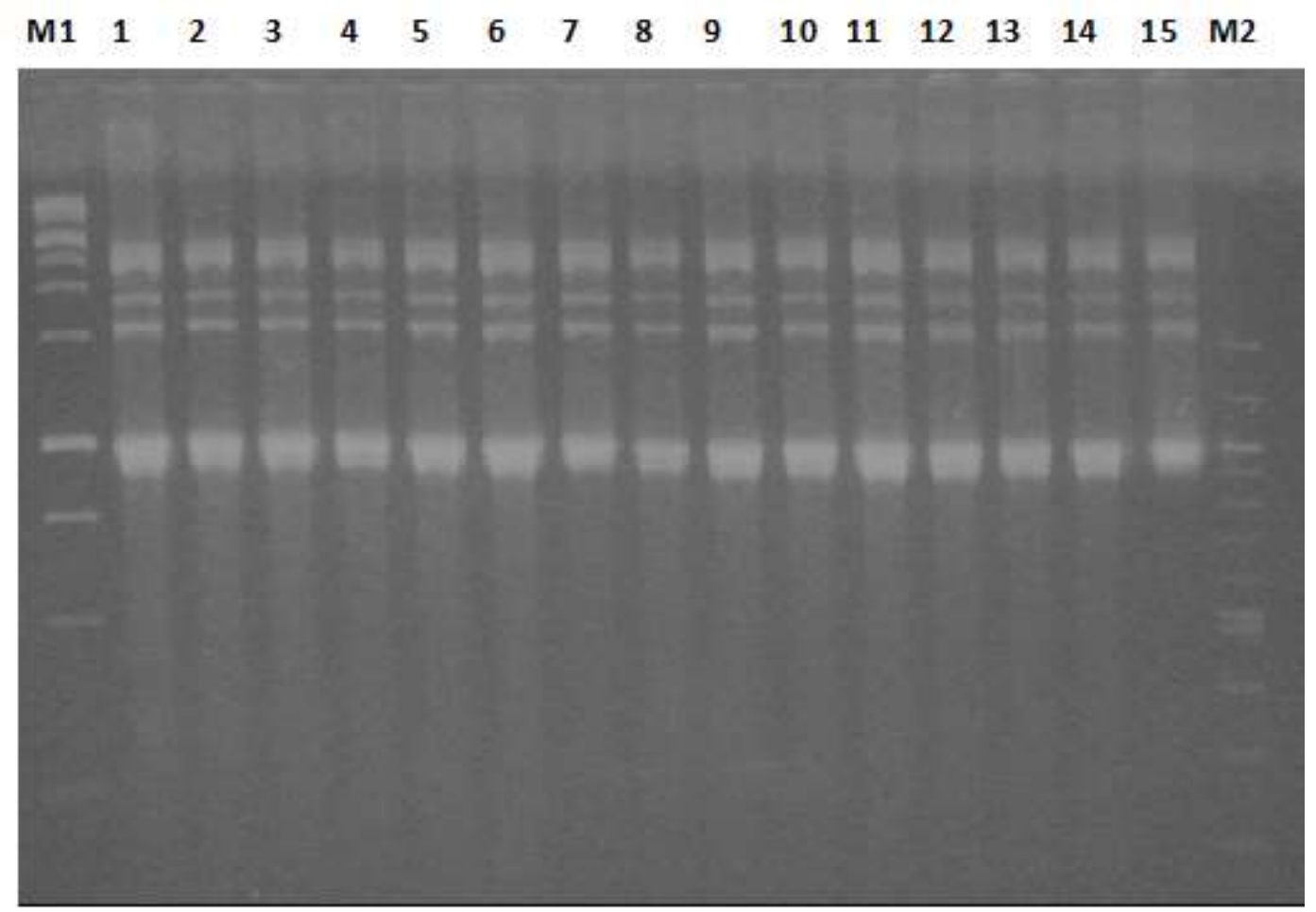

Figura 2. Análisis de diversidad genética de cepas de Pasteurella multocida aisladas de alpacas con neumonía, mediante la técnica BOX-PCR. M1: marcador de $1 \mathrm{~kb}$. Carril 1-15: cepas aisladas de alpaca. M2: marcador de $100 \mathrm{pb}$

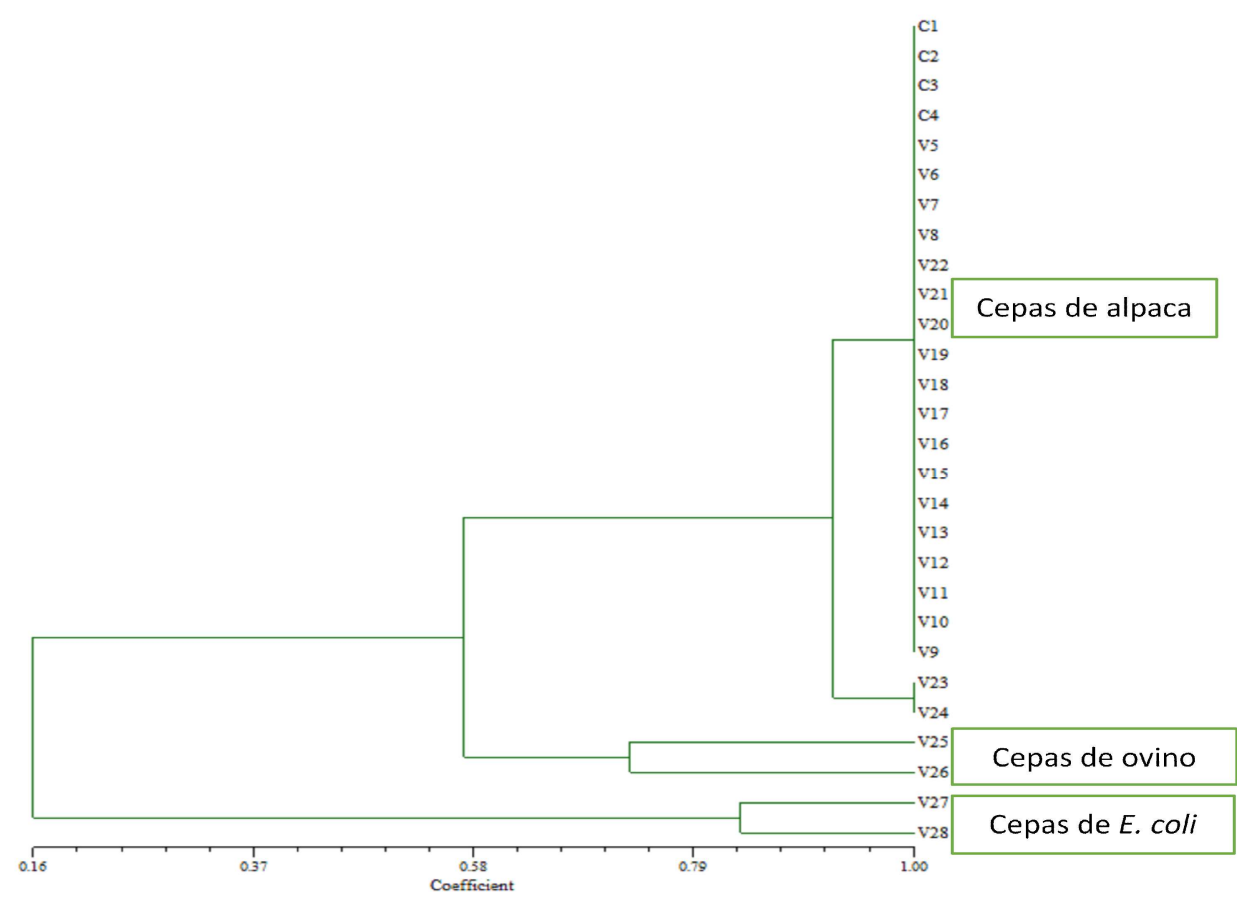

Figura 3. Dendograma del análisis por BOX-PCR de Pasteurella multocida y Escherichia coli 
pleando el método UPGMA (Unweighted Pair Group Method with Arithmetic Mean), basado en el coeficiente de similitud de DICE. La matriz de distancias se construyó a partir de datos binarios (presencia/ausencia de bandas) obtenidos del análisis de los BOX-PCR. Se emplearon dos aislados de $E$. coli de alpacas sin diarrea y las dos cepas de P. multocida de ovino para verificar el poder discriminatorio de la prueba.

\section{Resultados}

Para la estandarización del protocolo se analizaron las dos cepas de ovino (V25, V26) y dos cepas de alpaca, observándose que los aislados de alpacas mostraban el mismo número y peso molecular de bandas entre sí, pero distinto a lo observado en las cepas de ovino (Figura 1). Los 22 aislados restantes de alpaca mostraron el mismo patrón de amplificación (cantidades y tamaños de bandas), distintas a los dos aislados analizados inicialmente, resultando en un patrón de bandas distintas (Figura 2).

Asimismo, se realizó el análisis de dos cepas de E. coli (V27, V28) aisladas de alpacas sin diarrea del genotipo EPEC ( $E$. coli enteropatógena) para verificar la distinción entre los aislados de P. multocida de alpacas y ovinos. En la elaboración del dendograma se incluyeron los resultados de estas cepas de E. coli.

De acuerdo a los resultados obtenidos mediante el BOX-PCR, las cepas de $P$. multocida, tanto de ovino y de las alpacas, formaron clusters distintos, pero muy alejadas de las cepas de E. coli (V27, V28). Los aislados de alpacas fueron agrupados en dos clados (Figura 3).

\section{Discusión}

Las comparaciones entre los aislados de alpacas con las cepas de ovino demostraron- distintos fingerprinting (Figuras 1 y 2). Los aislados de $P$. multocida se agruparon en un cluster diferenciándose de las cepas de $E$. coli (EPEC) de alpaca, pudiendo discriminarse entre los dos géneros. Las cepas de ovino formaron un cluster, diferenciándose de los aislados de alpacas.

En general, se observó una baja diversidad entre los aislados de alpaca, evidenciándose como posible causa de la infección a una cepa de $P$. multocida que se diseminó clonalmente entre los animales afectados por neumonía (Figura 3). La posible causa de esta baja diversidad detectada podría ser por el sistema de empadre en el CIP-La Raya, donde tienen una «punta» de machos suris y huacayas que son llevados a las «puntas» de hembras para el empadre de las hembras, pudiendo ser el contacto un factor para la poca diversidad observada entre los aislados de alpacas, debido a que un solo animal infectado pudo haber diseminado la infección entre los individuos susceptibles. Esto concuerda con el estudio de Pedersen et al. (2003), con cepas de P. multocida de un brote en aves silvestres en 2001, comparándolas con una cepa que causó brotes en 1996 y 2003, obteniendo un patrón electroforético por la técnica de PFGE, concluyendo que una cepa había persistido durante años afectando a las aves.

En otro estudio, al analizar cepas de aves de corral, se detectó $70.3 \%$ de similitud en los análisis de ADN fingerprinting indicando que una cepa había persistido en el tiempo; sin embargo, al analizar la misma granja años más adelante, la tasa de similitud disminuyó drásticamente, debido a la introducción de nuevas cepas (nuevos clones), posiblemente por animales carnívoros como el zorro (Olson y Wilson, 2001). Esta misma situación también podría pasar en las alpacas, lo que sugiere realizar análisis adicionales en otros lugares y a través del tiempo.

Estos resultados podrían diferir a lo observado en otros estudios, donde se observa una significativa diversidad genética entre 
cepas de P. multocida aisladas de un brote de neumonía en bovinos; explicado quizás por la introducción de animales, variación genética, vacunación, etc. Sin embargo, esta diversidad fue difícil de interpretar porque todas las cepas fueron aisladas de un mismo brote (Taylor et al., 2010).

Esta técnica también ha sido empleada en Mannheimia haemolytica, bacteria también involucrada en la neumonía en alpacas y otras especies. Klyma (2007) comparó cepas de esta especie con cepas de la familia Pasteurellaceae provenientes de hisopado nasal de bovinos, donde la técnica BOX-PCR fue capaz de colocar correctamente en clusters todas las especies de Mannheimia.

En otro estudio, Actinobacillus pleuropneumoniae, agente bacteriano causante de neumonías en cerdos, fue analizado por BOX-PCR y otras secuencias del repPCR, encontrando una única banda en el 96.8\% de los aislados de A. pleuropneumonia, a diferencia de las otras cepas de $P$. multocida y Haemophilus parasuis tomados como cepas control, ubicando en otro cluster a estas cepas (César et al., 2013).

La baja diversidad genética de las cepas de $P$. multocida encontrada en el presente estudio resulta relevante al momento de desarrollar estrategias de control y prevención, así como la elaboración de vacunas contra las cepas circulantes de esta especie.

\section{Conclusiones}

- Los aislados de P. multocida de casos de neumonía en alpacas mostraron una baja diversidad genética entre ellas, indicando la participación de una misma cepa que se diseminó clonalmente y causó los casos clínicos de neumonía en alpacas.

- La técnica BOX-PCR permitió analizar aislados P. multocida de crías de alpacas con signos de neumonía.

\section{Agradecimientos}

Este estudio fue financiado por el Programa Nacional de Innovación para la Competitividad y Productividad - Innóvate Perú del Proyecto Contrato $\mathrm{N}^{\circ} 133$-FINCyTIB-2013 «Vacunología reversa: desarrollo de una vacuna de nueva generación para el control y/o prevención de la neumonía pasteurelósica en alpacas».

\section{Literatura Citada}

1. Ameghino E, DeMartini J. 1991. Mortalidad en crías de alpacas. Bol Divul IVITA, Perú: $128 \mathrm{p}$.

2. Barsallo J. 1985. Agentes bacterianos encontrados en el aparato respiratorio de alpacas adultas aparentemente normales. Anales V Convención Internacional sobre Camélidos Sudamericanos. Cusco, Perú.

3. César RC, Magno VA, Guimarães VW, Fernandes de Araujo E, Vieira de Queiroz M, Soares BDM. 2013. Face to face with Actinobacillus pleuropneumoniae: landscape of the distribution of clinical isolates in southeastern Brazil. Afr J Microbiol Res 7: 2916-2924. doi: 10.5897/AJMR12.2344

4. Cirilo CE. 2008. Identificación de agentes virales y bacterianos causantes de neumonías agudas en crías de alpacas. Tesis de Maestría. Lima: Univ Nacional Mayor de San Marcos. 93 p.

5. Dagleish MP, Bayne CW, Moon GG, Finlayson J, Sales J, Williams J, Hodgson JC. 2016. Differences in virulence between bovine-derived clinical isolates of Pasteurella multocida serotype A from the UK and the USA in a model of bovine pneumonic pasteurellosis. J Comp Pathol 155: 6271. doi: 10.1016/j.jcpa.2016.05.010

6. Foxman B, Zhang L, Koopman JS, Manning SD, Marrs CF. 2005. Choosing an appropriate bacterial typing technique for epidemiologic studies. 
Epidemiol Perspect Innov 2: 10. doi: 10.1186/1742-5573-2-10

7. Guzmán K. 2011. Identificación de polimorfismos del gen tlr4 en crías de alpacas con cuadros de neumonías por Pasteurella multocida. Tesis de Médico Veterinario. Lima: Univ Nacional Mayor de San Marcos. 70 p.

8. Ishii S, Sadowsky MJ. 2009. Applications of the rep-PCR DNA fingerprinting technique to study microbial diversity, ecology and evolution. Environ Microbiol 11 :733-740. doi: 10.1111/j.1462-2920.2008.01856.x

9. Klyma CL. 2007. Characterization of the genetic diversity and antimicrobial resistance in Mannheimia haemolytica from feedlot cattle. MSc Thesis. Canada. University of Lethbridge. $116 \mathrm{p}$.

10. Martin B, Humbert O, Camara M, Guenzi E, Walker J, Mitchell T, Andrew P, et al. 1992. A highly conserved repeated DNA element located in the chromosome of Streptococcus pneumoniae. Nucleic Acids Res 20: 3479-3483.

11. Olson LD, Wilson MA. 2001. DNA fingerprint patterns of Pasteurella multocida from the same turkey farm on the same and different years. Avian Dis 45: 807-812. doi: $10.2307 / 1592860$

12. Pedersen K, Dietz HH, Jorgensen JC, Christensen TK, Bregnballe T, Andersen TH. 2003. Pasteurella multocida from outbreaks of avian cholera in wild and captive birds in
Denmark. J Wildl Dis 39: 808-816. doi: 10.7589/0090-3558-39.4.808

13. Rosadio R, Cirilo E, Manchego A, Rivera $H .2011$. Respiratory syncytial and parainfluenza type 3 viruses coexisting with Pasteurella multocida and Mannheimia hemolytica in acute pneumonias of neonatal alpacas. Small Ruminant Res 97: 110-116. doi: 0.1016/ j.smallrumres.2011.02.001

14. Taylor JD, Fulton RW, Dabo SM, Lehenbauer TW, Confer AW. 2010. Comparison of genotypic and phenotypic characterization methods for Pasteurella multocida isolates from fatal cases of bovine respiratory disease. J Vet Diagn Invest 22: 366-375. doi: 10.1177/ 104063871002200304

15. Taylor JD, Doyle DJ, Blackall PJ, Confer AM. 2014. Use of rep-PCR and $16 \mathrm{~s}$ rRNA gene sequencing for comparison of Mannheimia haemolytica isolates obtained from fatal cases of bovine respiratory disease in the USA and Australia. Aust Vet J 92: 15-23. doi: 10.1111/avj.12137

16. Versalovic J, Schneider M, De Bruijn FJ, Lupski JR. 1994. Genomic fingerprinting of bacteria using repetitive sequence-based polymerase chain reaction. Methods Mol Cell Biol 5: 2540.

17. Yates WD. 1982. A review of infectious bovine rhinotracheitis, shipping fever pneumonia and viral-bacterial synergism in respiratory disease of cattle. Can J Comp Med 46: 225-263. 